\title{
ELECTROCHEMICAL STUDY OF POLYSULFIDE SOLUTIONS IN LIQUID AMMONIA
}

\author{
E. LEVILLAIN, C. JEHOULET, A. DEMORTIER and J.P. LELIEUR \\ URA 253 CNRS, HEI, 13 rue de Toul, F-59046 Lille cedex, France
}

\begin{abstract}
Résumé : Nous présentons les caractéristiques électrochimiques obtenues par voltampérométrie cyclique et par spectroscopie dimpédance pour les solutions de polysulfure de lithium et d'ammonium dans l'ammoniac liquide. Le comportement électrochimique dépend fortement du type de solution, conséquence de la dismutation de la plupart des ions polysulfures et du couplage des réactions de transfert d'électron avec des réactions chimiques en phase homogène.
\end{abstract}

\begin{abstract}
We present here the electrochemical characteristics obtained for cyclic voltammetry and impedance spectroscopy for lithium and ammonium polysulfide in liquid ammonia solutions. The observed electrochemical behaviour depends stongly on the type of solution, as a consequence of the disproportionation of most of the polysulfide ions and of the coupling of electron tranfer reactions with homogeneous chemical reactions.
\end{abstract}

\section{Introduction}

In solution, solvent or molten salts, the polysulfide ions are possibly subjected to three types of reaction /1/ :

- an homolytic dissociation leading to radical ions; the typical example is the well known equilibrium :

$$
\mathrm{S}_{6}{ }^{2-}<===2 \mathrm{~S}_{3}^{-}
$$

- a reaction of exchange of sulfur atoms :

$$
\mathrm{S}_{\mathrm{n}}^{2-}+\mathrm{x} / 8 \mathrm{~S}_{8} \Longleftrightarrow===\mathrm{S}_{\mathrm{n}+\mathrm{x}}{ }^{2-}
$$

This reaction has been used to prepare least reduced polysulfide from $\mathrm{S}^{2-}$. In presence of an excess of sulfur, the reaction stops when the least reduced polysulfide in the solvent is obtained; the solution contains $S_{8}$ and $S_{\max }{ }^{2-}$.

- a disproportionation reaction of the type :

$$
2 \mathrm{~S}_{\mathrm{n}}^{2-}<====\mathrm{S}_{\mathrm{n}-1}{ }^{2-}+\mathrm{S}_{\mathrm{n}+1^{2-}}
$$

These polysulfides can also be partly or totally disproportionated; as a consequence, the stoichiometry of a disproportionation reaction of a given polysulfide ion can be complex and depend on the nature of the 
solvent. An other consequence of this type of reaction : when a solvent is added to a solid of overall composition $\mathrm{Li}_{2} \mathrm{~S}_{\mathrm{n}}$, the resulting solution may usually contain, at equilibrium, several polysulfide ions.

In liquid ammonia, the following informations have been obtained by spectroscopic techniques 12,3/ :

$-S_{6}^{2-}$ is the least reduced polysulfide. This ion is not disproportionated in neutral solutions and is always in equilibrium with $\mathrm{S}_{3}{ }^{-}$

- $S_{5}{ }^{2-}$ is strongly, if not totally, disproportionated.

- $\mathrm{S}_{4}{ }^{2-}$ is only partially disproportionated. This has been shown by the observation of $\mathrm{S}_{3}^{-}$(UVvisible, Raman, ESR) in the solutions. The reduced species cannot be identified by these techniques because the various polysufides $S_{n}^{2-}$ absorb at the same wavelengths (300- $400 \mathrm{~nm}$ ).

- The polysulfide ions are always more disproportionated in acidic $\left(\mathrm{NH}_{4}{ }^{+}\right)$solutions. This behavior is due to the displacement of the disproportionation reactions by the acid-base reaction

$$
\mathrm{S}^{2-}+\mathrm{NH}_{4}^{+}<===\mathrm{HS}^{-}+\mathrm{NH}_{3}
$$

since it has been shown that HS- $^{-}$is the only protonated sulfur species in liquid ammonia.

From a formal point of view, the oxidation number of a polysulfide ion $S_{n}{ }^{2-}$ is $-2 / n$. The reactions of the polysulfides ions can be considered as redox reactions and studied by electrochemical techniques. In this communication, we present the contribution of electrochemistry to the knowledge of polysulfide ions solutions.

\section{Experimental.}

$\mathrm{Li}_{2} \mathrm{~S}_{\mathrm{n}}$ and $\left(\mathrm{NH}_{4}\right)_{2} \mathrm{~S}_{\mathrm{n}}$ solutions are prepared by reduction of sulfur with Lithium or $\mathrm{H}_{2} \mathrm{~S}$ in stoichiometric amount. The details of this preparation have been described in detail elsewhere $14,5 /$.

The cyclic voltammetry have been performed with a potentiostat EGG 273 and a three electrodes cell. The auxilary electrode was in gold or tungsten. The working electrode was a stationary gold disk electrode $2 \mathrm{~mm}$ in diameter. A gold or tungsten wire located near the working electrode was used as a pseudo-reference electrode. This is possible, because the various polysulfide ions are more or less disproportionated; the redox level of the solutions is always very well defined. Due to this set-up, the design of the cell was simple and temperature up to $10^{\circ} \mathrm{C}$ can be attained. For the study of $\mathrm{Li}_{2} \mathrm{~S}_{4}$ and $\left(\mathrm{NH}_{4}\right)_{2} \mathrm{~S}_{4}$ solutions around the equilibrium potential, the addition of a supporting electrolyte was not necessary : the concentration of the electroactive species is very low compared to the concentration of $\mathrm{Li}^{+}$and $\mathrm{S}_{4}{ }^{2-}$ ions. For other solutions and for the analysis at large overvoltages, $\mathrm{LiNO}_{3}$ was used as the supporting electrolyte. For cyclic voltammetry experiments, the initial potential was the equilibrium potential (overvoltage $=0$ ). From this value, the initial scan direction may be positive or negative.

The electrochemical impedance were measured beween $10^{4.8}$ and $10^{-2}$ or $10^{-3} \mathrm{~Hz}$ (10 or 20 points per decade) with the Solartron 1250 frequency response analyzer and the Solartron 1286 electrochemical interface. When possible, the experiments where run on the same cells as the voltammetric experiments. For the purpose of clarity only 5 points per decade are displayed in the figures. 


\section{$\mathrm{Li}_{2} \mathrm{~S}_{4}-\mathrm{NH}_{3}$ solutions at the equilibrium potential.}

The experimental results obtained from cyclic voltammetry and electrochemical impedance for $\mathrm{Li}_{2} \mathrm{~S}_{4}-\mathrm{NH}_{3}$ solutions give evidence of a simple electron transfer reaction in a solution containing both the oxidized and the reduced form of a redox couple :

$$
\mathrm{Ox}+\mathrm{n} \text { e- } \Longleftrightarrow=\mathrm{R}
$$

The existence of a well defined equilibrium potential, the shape of the voltammograms (Fig 1), the influence of the initial scan direction and of the scan rate are in close agreement with the conclusions of a theoretical study of such a system $/ 6 /$. The electrochemical impedance at the equilibrium potential in moderately concentrated solutions (Fig 2) confirms this conclusion. The small semi-circle observed at high frequency suggests a relatively fast electron transfer reaction and the Warburg line at low frequency is typical of the diffusion of the electroactive species.

We have shown $/ 4 /$ that the coupling of the theory of cyclic voltammetry and electrochemical impedance with the experimental results with these techniques in a wide range of concentration and temperature gives, whithout any assumption, the number of electrons involved in the electrochemical reaction. Only a one electron transfer reaction can account for the experimental results.
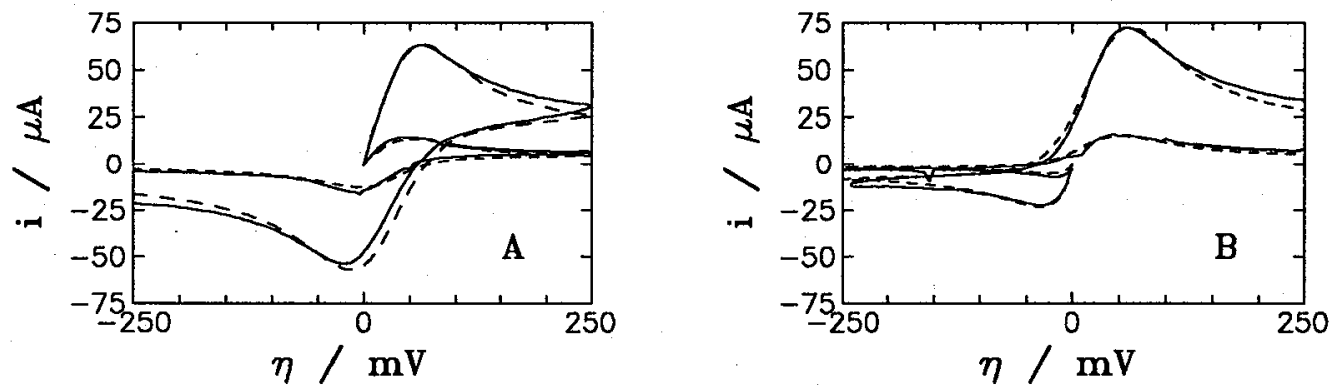

Fig 1. Cyclic voltammograms of a $0.36 \mathrm{M} \mathrm{Li}_{2} \mathrm{~S}_{4}$ solution at $252 \mathrm{~K}$; scan rates : 500 and $20 \mathrm{mV} \mathrm{s} \mathrm{s}^{-1}$ (A) positive initial scan direction; (B) negative initial scan direction.

( $\left(-\right.$ ) experimental ; $\left(---_{-}\right)$theoretical
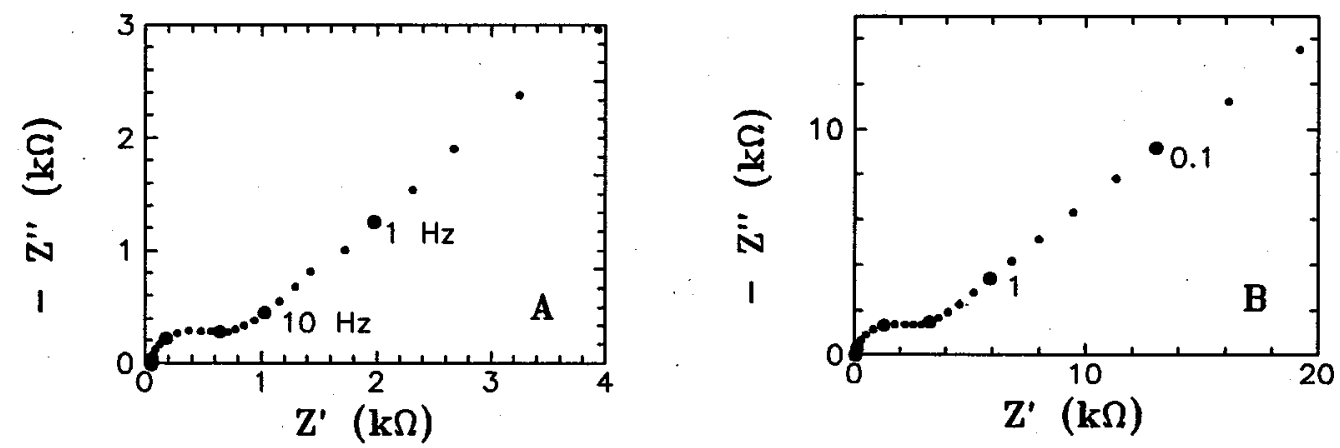

Fig 2. Impedance diagram of a $0.72 \mathrm{M} \mathrm{Li}_{2} \mathrm{~S}_{4}$ solution on platinum (electrode area: $0.031 \mathrm{~cm}^{2}$ ). (A) $257 \mathrm{~K}$; (B) $243 \mathrm{~K}$. 
The order of magnitude of the peak currents observed in cyclic voltammetry is weak. An estimate of the concentration of the electroactive species suggest that these concentrations are smaller by two ordres of magnitude than the analytical concentration of the solutions and it can be concluded that the electroactive species are polysulfide ions resulting from the disproportionation of $\mathrm{S}_{4}{ }^{2-}$. The spectroscopic experiments have shown that $S_{6}{ }^{2-}$ and $S_{3}{ }^{-}$are the only polysulfides more oxidized than $S_{4}{ }^{2-}$ and that the concentration of $\mathrm{S}_{3}{ }^{-}$increases with temperature. In $\mathrm{Li}_{2} \mathrm{~S}_{4}-\mathrm{NH}_{3}$ solutions, ESR experiments show that only one radical species, $\mathrm{S}_{3}{ }^{-}$, is present in solution $/ 7 /$. This radical is the only singled charged species that can accept one electron. These arguments lead to the identification of $\mathrm{S}_{3}{ }^{-}$as the oxidized species of the redox couple. Therefore, the electrochemical reaction in the solution is :

$$
\mathrm{S}_{3}^{-}+\mathrm{e}^{-}<===>\mathrm{S}_{3}{ }^{2-}
$$

This conclusion is supported by several experimental observations: $i$ the variation of the cathodic peak currents with temperature, $i i$ their variation, with the analytical concentration of the solution, which follows that of the ESR signal $/ 4,7 /$, iii the variation of the shape of the voltammograms with the stoichiometry of the solution $(3.5<n<4.5)$. It must be noted that $S_{3}{ }^{2-}$ cannot be identified by spectroscopy in $\mathrm{Li}_{2} \mathrm{~S}_{4}$ solutions.

On the base of the conclusions derived above, the disproportionation reaction of $\mathrm{S}_{4}{ }^{2-}$ may be written, as a first approximation, as :

$$
3 \mathrm{~S}_{4}^{2-}<===\Rightarrow 2 \mathrm{~S}_{3}^{2-}+\mathrm{S}_{6}^{2-} \quad \text { with } \mathrm{S}_{6}{ }^{2-} \text { in equilibrium with } \mathrm{S}_{3}^{-}
$$

This reaction is based on the assumption of the total disproportionation of $\mathrm{S}_{5}{ }^{2-}$ ion in liquid ammonia. The experimental results show that the electrochemical properties are characteristic of a simple redox reaction and that the competition of homogeneous chemical reactions can be ignored. The chemical system can be considered as frozen on the time scale of the electrochemical experiments: the kinetics of the disproportionation reaction is rather slow. An estimate of the concentration of the electroactive species, based on an hypothesis for the diffusion coefficient, indicates that $\mathrm{S}_{4}{ }^{2-}$ is only partly disproportionated: the concentrations of $\mathrm{S}_{3}^{-}$and $\mathrm{S}_{3}{ }^{2-}$ are always less than $1 \%$ of the analytical concentration.

\section{$\left(\mathrm{NH}_{4}\right)_{2} \mathrm{~S}_{4}-\mathrm{NH}_{3}$ solutions at the equilibrium potential.}

The experimental data for $\left(\mathrm{NH}_{4}\right)_{2} \mathrm{~S}_{4}-\mathrm{NH}_{3}$ solutions at the equilibrium potential appear to be very different from those found for $\mathrm{Li}_{2} \mathrm{~S}_{4}$. For cylic voltammetry (Fig 3), when the initial scan direction is negative, a reduction peak current is observed; on the reverse scan, an anodic peak is displayed for the highest scan rates, which show that there is some reversibility of the electrochemical reaction. When the initial scan direction is positive, an anodic plateau almost independent of the scan rate is displayed. These obsevations are explained by the following model $/ 4,6 /$ :

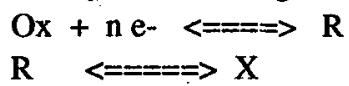

with $\mathrm{Ox}, \mathrm{R}$ and $\mathrm{X}$ initially present in solution. The low intensity of the anodic plateau shows that the reaction is shifted strongly to the right. The observation, for high scan rates and low temperatures, of the reoxidation of $R$ and of the anodic plateau independence from the scan rate show that the kinetics of the chemical reaction limit the oxidation current. 

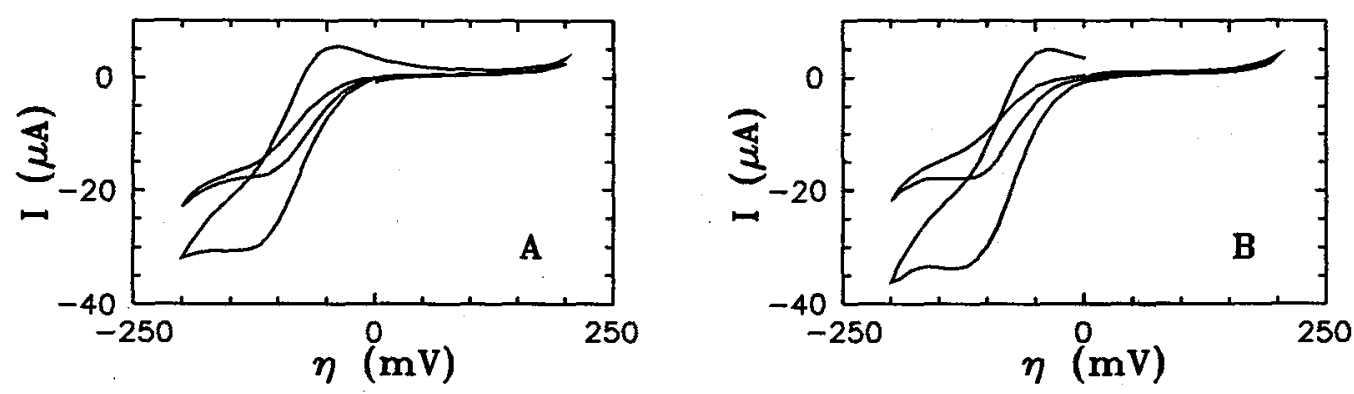

Fig 3. Cyclic voltammograms of a $0.24 \mathrm{M}\left(\mathrm{NH}_{4}\right)_{2} \mathrm{~S}_{4}$ solution at $252 \mathrm{~K}$; scan rate : 100 and $10 \mathrm{mV} \mathrm{s}^{-1}$ (A) negative initial scan direction; (B) positive initial scan direction.
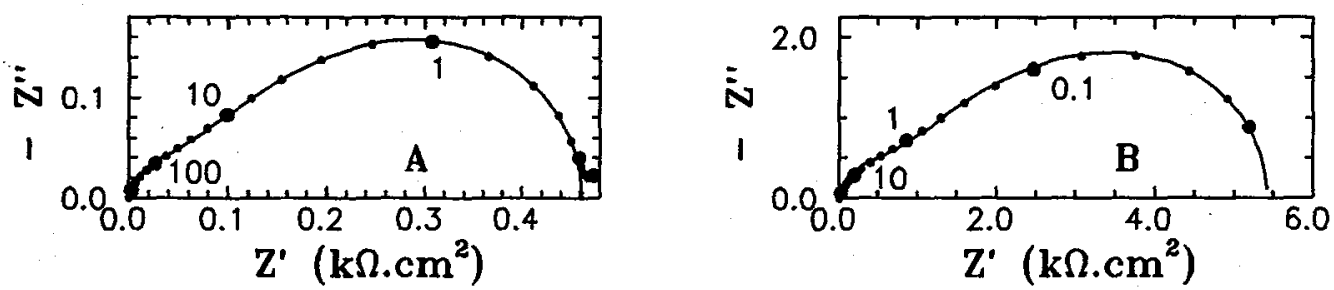

Fig 4. Impedance diagram of a $0.128 \mathrm{M}\left(\mathrm{NH}_{4}\right)_{2} \mathrm{~S}_{4}$ solution on platinum. (A) $263.7 \mathrm{~K}$; (B) $231.9 \mathrm{~K}$.
( $)$ experimental data; ( ) best fit.

The shape of the impedance diagram (Fig 4) also suggests a Gerischer profile /8/ which is expected for the $E_{R}$ mechanism given above (electrochemical reaction, $E$, coupled with a reversible chemical reaction, $\mathrm{C}_{\mathrm{R}}$ ).

Since it has been shown by spectroscopic techniques that $\mathrm{S}_{4}{ }^{2-}$ is also disproportionated in solutions of ammonium tetrasulfide in liquid ammonia, it is deduced that $S_{3}{ }^{-}$and $S_{3}{ }^{2-}$ are present in solution. From the voltammograms it can be concluded that the reduced species, $\mathrm{S}_{3}{ }^{2-}$, is in equilibrium with another species. Since this phenomenon is not observed for $\mathrm{Li}_{2} \mathrm{~S}_{4}-\mathrm{NH}_{3}$ solutions, the chemical reaction must involve the $\mathrm{NH}_{4}{ }^{+}$ions. The kinetic parameter of the chemical reaction can be obtained by a quantitative analysis of the impedance diagram. The variations of this parameter as a function of temperature and of the analytical concentration also suggest that the main factor is the ammonium ion concentration. It has been shown that $\mathrm{HS}^{-}$is the only protonated sulfur species and that $\mathrm{S}_{3}{ }^{2-}$ and $\mathrm{S}_{2}{ }^{2-}$ are at least partly disproportionated in ammonium solutions. The equilibrium reaction is certainly more complex than a simple first order reaction and must proceed in several steps involving protonation and disproportionation reactions. Several reaction mechanisms can be written. This subject is under study by impedance spectroscopy for $\left(\mathrm{NH}_{4}\right)_{2} \mathrm{~S}_{\mathrm{n}}-\mathrm{NH}_{3}$ solutions $(1<\mathrm{n}<6)$. 


\section{$\mathrm{Li}_{2} \mathrm{~S}_{\mathrm{n}}-\mathrm{NH}_{3}$; large overvoltages.}

The knowledge of the electrochemical properties of $\mathrm{Li}_{2} \mathrm{~S}_{\mathrm{n}}-\mathrm{NH}_{3}$ solutions at the equilibrium potential has made possible the progress in the understanding of the behaviour of $\mathrm{Li}_{2} \mathrm{~S}_{\mathrm{n}}$ solutions for large overvoltages. In this paper, we limit the discussion to the results obtained for one concentration $(\mathrm{C}=0.036 \mathrm{M})$ and one temperature $\left(0^{\circ} \mathrm{C}\right)$ for the same scan rate $(0.2 \mathrm{V.s}-1)$.
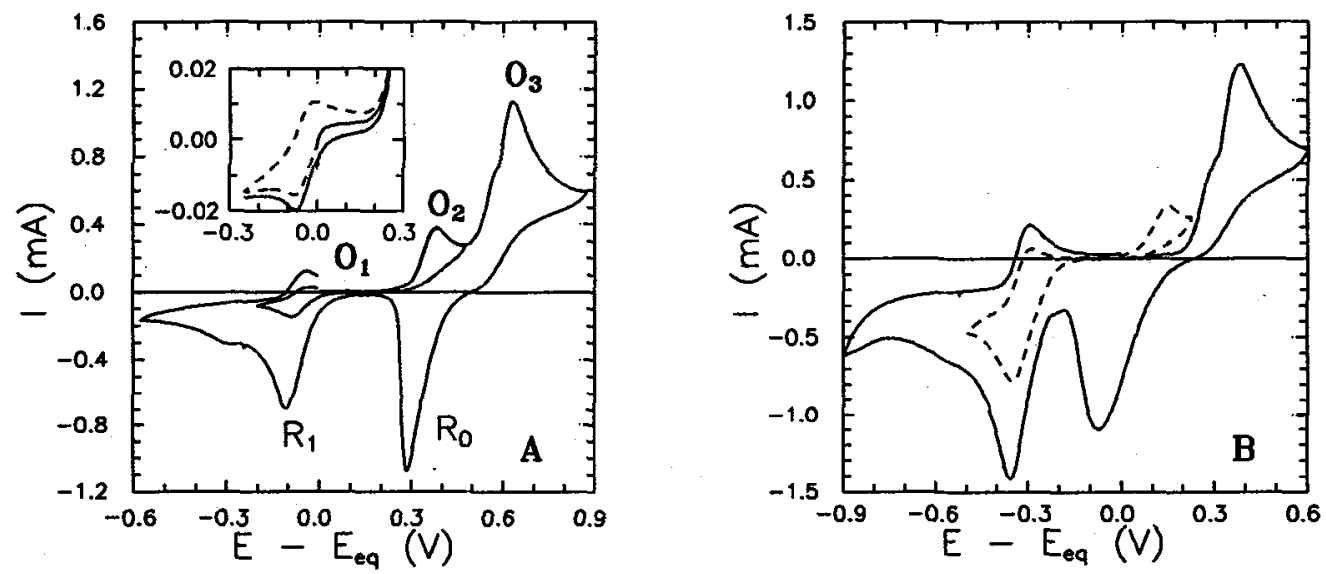

Fig 5 Cyclic voltammograms of $0.036 \mathrm{Li}_{2} \mathrm{~S}_{\mathrm{n}} ; 0.2 \mathrm{~V} \mathrm{~s}^{-1} ; 273 \mathrm{~K}$. (A) $\mathrm{Li}_{2} \mathrm{~S}_{4} ;$ (B) $\mathrm{Li}_{2} \mathrm{~S}_{6}$

( $\longrightarrow$ ) : positive initial scan direction; $(\ldots \ldots+\ldots)$ : negative initial scan direction.

Fig 5 a displays the experimental data for a $\mathrm{Li}_{2} \mathrm{~S}_{4}$ solution. The characteristics around the equilibrium potential, plotted in the insert, are similar to those of Fig 1; the reduction peak is noted $R_{1}$ and the oxidation peak, $\mathrm{O}_{1}$. When the initial scan direction is positive, an oxidation peak $\mathrm{O}_{2}$ is observed. This peak is assigned to the oxidation of $\mathrm{S}_{4}{ }^{2-}$, the only species present in solution at high concentration. When the potential scan is switched immediatly after $\mathrm{O}_{2}$, an increase in current for $R_{1}$ is observed: the irreversible oxidation of $\mathrm{S}_{4}{ }^{2-}$ leads to the formation of $\mathrm{S}_{6}{ }^{2-}+\mathrm{S}_{3}{ }^{-}$. When the overvoltage is larger than the value related to $\mathrm{O}_{2}$, a large irreversible peak, $\mathrm{O}_{3}$, is observed. It will be show later that this peak must be assigned to the oxidation of $S_{6}{ }^{2-}+S_{3}-$. The peak $R_{0}$, observed on the reverse scan is due to the species formed during the oxidation $\mathrm{O}_{3}$. The shape of this peak is typical of an insoluble species precipitated on the electrode. By comparison with the cyclic voltammograms of solutions of $S_{8}$ in non aqueous solvents, DMSO $19,10 /$ and DMF /10/, we assign this peak to the reduction of insoluble $S_{8}$ deposited on the electrode. It must be noted that $S_{8}$ is highly soluble in liquid ammonia; however the dissolution is rather slow even at room temperature. An other confirmation of this assignment, is the large peak $R_{1}$ following $R_{0}$ : as in DMSO and DMF, the reduction of $S_{8}$ leads to the formation of $S_{6}{ }^{2-}+S_{3}-$.

The results for $\mathrm{Li}_{2} \mathrm{~S}_{6}$ (Fig $5 \mathrm{~b}$ ) are coherent with these conclusions. When the scan direction is positive, the peak $\mathrm{O}_{2}$ is not observed since the solution does not contain $\mathrm{S}_{4}{ }^{2-}$. The peak $\mathrm{O}_{3}$, the first oxidation process observed must be assigned to $S_{6}{ }^{2-}+S_{3}{ }^{-}$. When the scan direction is negative, as 
expected, the peak current for $\mathrm{R}_{1}$ is larger than in $\mathrm{Li}_{2} \mathrm{~S}_{4}$ solutions. On the reverse scan, the oxidation peak $\mathrm{O}_{2}$, associated to $\mathrm{S}_{4}{ }^{2-}$, is observed. The reduction of $\mathrm{S}_{3}{ }^{-}$gives $\mathrm{S}_{3}{ }^{2-}$; these two species react in the diffusion layer to produce $S_{4}{ }^{2-}$; this reaction, the opposite of the disproportionation reation of $S_{4}{ }^{2-}$ is rather fast.

The experimental results for a solution of overall composition $\mathrm{Li}_{2} \mathrm{~S}_{5}$ are consistent with these observations. Due to the absence of a "true" reference electrode, the peak potentials are function of the stoichiometry of the solutions. However, it is possible to reference all the potentials to the same origin: the potential of the peak $R_{1}$. The same values (within the experimental errors) are obtained for $\mathrm{O}_{1}, \mathrm{O}_{2}$, $\mathrm{O}_{3}$ and $\mathrm{R}_{0}$ for all types of solutions, and also for sulfur and $\left(\mathrm{NH}_{4}\right)_{2} \mathrm{~S}_{\mathrm{n}}$ solutions. These values show that the peaks correspond to the same electrochemical phenomema in all types of solution.

\section{Conclusion.}

The electrochemical properties of $\mathrm{Li}_{2} \mathrm{~S}_{\mathrm{n}}$ and $\left(\mathrm{NH}_{4}\right)_{2} \mathrm{~S}_{\mathrm{n}}$ solutions in liquid ammonia at the equilibrium potential give informations on the equilibrium state of these solutions. They confirm and complete the conclusions of the spectroscopic techniques.

The results presented in this paper for $\mathrm{Li}_{2} \mathrm{~S}_{\mathrm{n}}-\mathrm{NH}_{3}$ solutions are preliminary and their interpretation is largely qualitative. They show that it will be possible to assign and understand the oxydation and reduction waves in $\mathrm{Li}_{2} \mathrm{~S}_{\mathrm{n}}$ and $\left(\mathrm{NH}_{4}\right)_{2} \mathrm{~S}_{\mathrm{n}}$ solutions. With the exception of the system $\mathrm{S}_{3}{ }^{-} / \mathrm{S}_{3}{ }^{2-}$, the electrochemical systems are irreversible and may correspond to slow electron transfer reactions or/and to electron transfer coupled to irreversible homogeneous chemical reactions.

These results also show that the radical ion $\mathrm{S}_{3}{ }^{-}$plays a key role in the electron tranfer reactions in these solutions.

Acknowledgements : The authors thank Professor G. Lepoutre for stimulating discussions. They express their gratitude to the CNRS, the Région Nord-Pas de Calais and the fondation Norbert Segard for fellowships to C.J. and E.L..

\section{References}

/1/ Badoz-Lambling, J., Bonnaterre, R., Cauquis, G., Delamar, M., Demange, G., Electrochim. Acta 21 (1976) 119

12/ Dubois, P., Lelieur, J.P., Lepoutre, G., Inorg. Chem. 27 (1988) 73

13/ Dubois, P., Lelieur, J.P., Lepoutre, G., Inorg. Chem. 27 (1988) 1883

14/ Jehoulet, C., Demortier, A., Lelieur, J.P., J. Electroanal. Chem. 292 (1990) 153

15/ Jehoulet, C., Demortier, A., Lelieur, J.P., J. Electroanal. Chem. 296 (1990) 77

16/ Demortier, A., Jehoulet, C., J. Electroanal. Chem. 283 (1990) 15

17 Pinon, V., Thèse Lille (1990)

181 Gerischer, H., Z. Phys. Chem. 198 (1951) 286

$19 /$ Martin, P., Doub, W.H., Roberts, J.L., Sawyer, D.T., Inorg. Chem. 12 (1973) 1921

/10/ Levillain, E., Demortier, A., unpublished results 